\title{
Vulnerabilities to and the Socioeconomic and Psychosocial Impacts of the Leishmaniases: A Review
}

\begin{abstract}
Grace Grifferty, ${ }^{\prime}$ Hugh Shirley, 2,3 Jamie McGloin, ${ }^{4}$ Jorja Kahn, (iD ${ }^{5}$ Adrienne Orriols, ${ }^{5}$ Richard Wamai ${ }^{6}$

'Department of Biology, Northeastern University, College of Science, Boston, MA, USA; ${ }^{2}$ Department of Biochemistry,

Northeastern University, College of Science, Boston, MA, USA; ${ }^{3}$ Program in Medical

Education, Harvard Medical School, Boston, MA, USA; ${ }^{4}$ Department of Health Sciences, Northeastern University, Bouvé College of Health Sciences, Boston, MA, USA; ${ }^{5}$ Department of Behavioral Neuroscience, Northeastern University, College of Science, Boston, MA, USA; ${ }^{6}$ Department of Cultures, Societies and Global Studies, Northeastern University, College of Social Sciences and Humanities, Integrated Initiative for Global Health, Boston, MA, USA
\end{abstract}

\section{Video abstract}

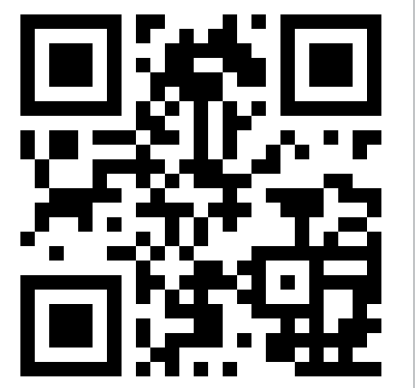

Point your SmartPhone at the code above. If you have a $Q R$ code reader the video abstract will appear. Or use: https://youtu.be/2KEaHJAvDPE

Correspondence: Richard Wamai, Department of Cultures, Societies and Global Studies, Northeastern University, College of Social Sciences and Humanities, Integrated Initiative for Global Health, 20 I

Renaissance Park, 360 Huntington Ave,

Boston, MA, 02115, USA

$\mathrm{Tel}+$ I 6173734130

Fax +I 6173732625

Email r.wamai@northeastern.edu
Abstract: The leishmaniases are a group of four vector-borne neglected tropical diseases (NTDs) with 1.6 billion people in some 100 countries at risk. They occur in certain ecoepidemiological foci that reflect manipulation by human activities, such as migration, urbanization and deforestation, of which poverty, conflict and climate change are key drivers. Given their synergistic impacts, risk factors and the vulnerabilities of poor populations and the launch of a new 2030 roadmap for NTDs in the context of the global sustainability agenda, it is warranted to update the state of knowledge of the leishmaniases and their effects. Using existing literature, we review socioeconomic and psychosocial impacts of leishmaniasis within a framework of risk factors and vulnerabilities to help inform policy interventions. Studies show that poverty is an overarching primary risk factor. Low-income status fosters inadequate housing, malnutrition and lack of sanitation, which create and exacerbate complexities in access to care and treatment outcomes as well as education and awareness. The co-occurrence of the leishmaniases with malnutrition and HIV infection further complicate diagnosis and treatment, leading to poor diagnostic outcomes and therapeutic response. Even with free treatment, households may suffer catastrophic health expenditure from direct and indirect medical costs, which compounds existing financial strain in low-income communities for households and healthcare systems. The dermatological presentations of the leishmaniases may result in long-term severe disfigurement, leading to stigmatization, reduced quality of life, discrimination and mental health issues. A substantial amount of recent literature points to the vulnerability pathways and burden of leishmaniasis on women, in particular, who disproportionately suffer from these impacts. These emerging foci demonstrate a need for continued international efforts to address key risk factors and population vulnerabilities if leishmaniasis control, and ultimately elimination, is to be achieved by 2030 .

Keywords: leishmaniasis, risk factors, economic-psychosocial impacts, neglected tropical diseases, kala-azar

\section{Introduction}

Ancient, debilitating and stigmatizing, the leishmaniases are among the neglected tropical diseases (NTDs) globally impacting nearly two billion people. ${ }^{1-5}$ Representing parasitic, bacterial, viral, helminths and protozoan infections, ${ }^{4,5}$ NTDs are aptly called "diseases of the poor" because they are all strongly connected to poverty and impoverished environments even in high-income countries. ${ }^{6,7}$ The human health effects of NTDs are disproportionately distributed by disease 
type, gender and age. In particular, the leishmaniases stand out for their socioeconomic impacts, where various economic variables act as proxies for a range of important global risk factors, such as type of housing, malnutrition, livelihood patterns, labor migration and resource conflicts. $^{8-16}$ The most severe form of leishmaniasis has been shown to cause significant financial and economic loss to as much as $75 \%$ of households affected by the disease in Asia and Africa. ${ }^{17-21}$ Annualized loss in productive economic input has been estimated to be $6-30 \%$ among affected households in a global assessment. ${ }^{22}$ Several recent systematic reviews have further highlighted significant economic impacts. ${ }^{23,24}$

The leishmaniases manifest in four severely neglected forms, namely visceral leishmaniasis (VL) (also known as Kala-azar), cutaneous leishmaniasis (CL), post-kala-azar dermal leishmaniasis (PKDL) and mucocutaneous leishmaniasis (MCL) ${ }^{25,26}$ Endemic in some 100 countries, the leishmaniases are vector-borne diseases caused by about 20 species of protozoan parasites of the genus Leishmania and transmitted through a bite of infected female phlebotomine sandflies of over 90 species. ${ }^{25,27,28}$ Due to poor programming and reporting, the true level of disease prevalence is unknown. It is estimated that 1.6 billion of the world's population lives in areas of potential risk of leishmaniases transmission. ${ }^{29}$ With climate change, population growth and migration, this figure could increase in the years ahead. The World Health Organization (WHO) estimates that 50,000 to 90,000 and 600,000 to 1 million annual cases of $\mathrm{VL}$ and $\mathrm{CL}$ occur worldwide, respectively. ${ }^{30}$ However, the latest data reported to the WHO from 98 countries in 2018 identified 17,223 cases of VL and 253,435 cases of CL, ${ }^{31}$ a vast underrepresentation that speaks to the neglected nature of these diseases. Cases are distributed almost equally across sub-Saharan Africa, Southeast Asia, the Middle East and Latin America $^{32}$ with just ten countries (Brazil, China, Ethiopia, India, Iraq, Kenya, Nepal, Somalia, South Sudan and Sudan) reporting $95 \%$ of VL cases and ten (Afghanistan, Algeria, Bolivia, Brazil, Colombia, Iran (Islamic Republic of), Iraq, Pakistan, the Syrian Arab Republic and Tunisia) reporting $85 \%$ of CL cases. ${ }^{30}$ Table 1 captures important characteristics for the leishmaniases in each of these countries.

When left untreated, VL has been reported to result in 95\% fatality and can result in PKDL. ${ }^{27,33,34} \mathrm{CL}$ is a disfiguring and stigmatizing disease characterized by skin lesions, mainly ulcers, on exposed parts of the body that leave life-long scars, cause disability and severe psychosocial and mental health outcomes..$^{25,27,35-39}$ The contribution of VL to the disability-adjusted life years (DALYs) for all NTDs is among the highest ${ }^{40}$ at $97 \%$ of the 774,000 DALYs from the leishmaniases. ${ }^{41,42}$

Historically, epic campaigns to end NTDs represent what the WHO has called a 'rags-to-riches story' ${ }^{43}$ because these are some of the best pro-poor health policies and interventions to break the cycles of poverty caused by these diseases, thus presenting a strong case for accelerated investments. ${ }^{22}$ NTDs are the reason why the World Bank started working in the health sector decades ago in the 1970s. ${ }^{44}$ Expanding our understanding of the scale and scope of the socioeconomic impacts of NTDs, such as the leishmaniases, is timely for several important reasons. First, at the start of 2021, the WHO launched the 2030 NTDs Roadmap. ${ }^{45}$ This Roadmap follows the 2020 Roadmap launched in 2012, where global organizations began an unprecedented and intensified focus on NTDs in what emerged as the London Declaration on NTDs. ${ }^{46,47}$ While the 2020 Roadmap accelerated efforts with various accomplishments, most targets related to the leishmaniases were missed. ${ }^{48}$ Secondly, the new 2030 Roadmap is aligned with the global United Nations Sustainable Development Goals (SDGs), in which "the end of NTDs" by 2030 is called for with eradication of chronic poverty as the top goal. ${ }^{49}$ Third, understanding the impoverishing conditions in the cycle of leishmaniasis transmission is critical for the elimination of disease, with the current goal being $<1$ case per 10,000 inhabitants. ${ }^{50}$ Of the 736 million people living in poverty in $2015,{ }^{51}$ most reside in leishmaniasis-endemic regions (Table 1). ${ }^{29}$ Although the global population living in poverty over the past two decades in low- and middle-income countries has been declining, it is necessary to assess persistence in vulnerability for regions where leishmaniasis is still largely prevalent. Fourth, the disruption of interventions caused by the raging COVID-19 pandemic threatens to set back years of progress on NTDs and related SDGs poverty targets because of synergistic exacerbating effects $^{52-55}$ and further threatens the attainment of the 2030 NTDs Roadmap. Fifth, 17\% of the global burden of infectious diseases is from vector-borne diseases including the leishmaniases and the effect of climate change on these diseases is likely to get worse. ${ }^{56}$ Using existing literature, here we examine the socioeconomic and psychosocial impacts of leishmaniases, as well as exacerbating factors that can help inform policy 


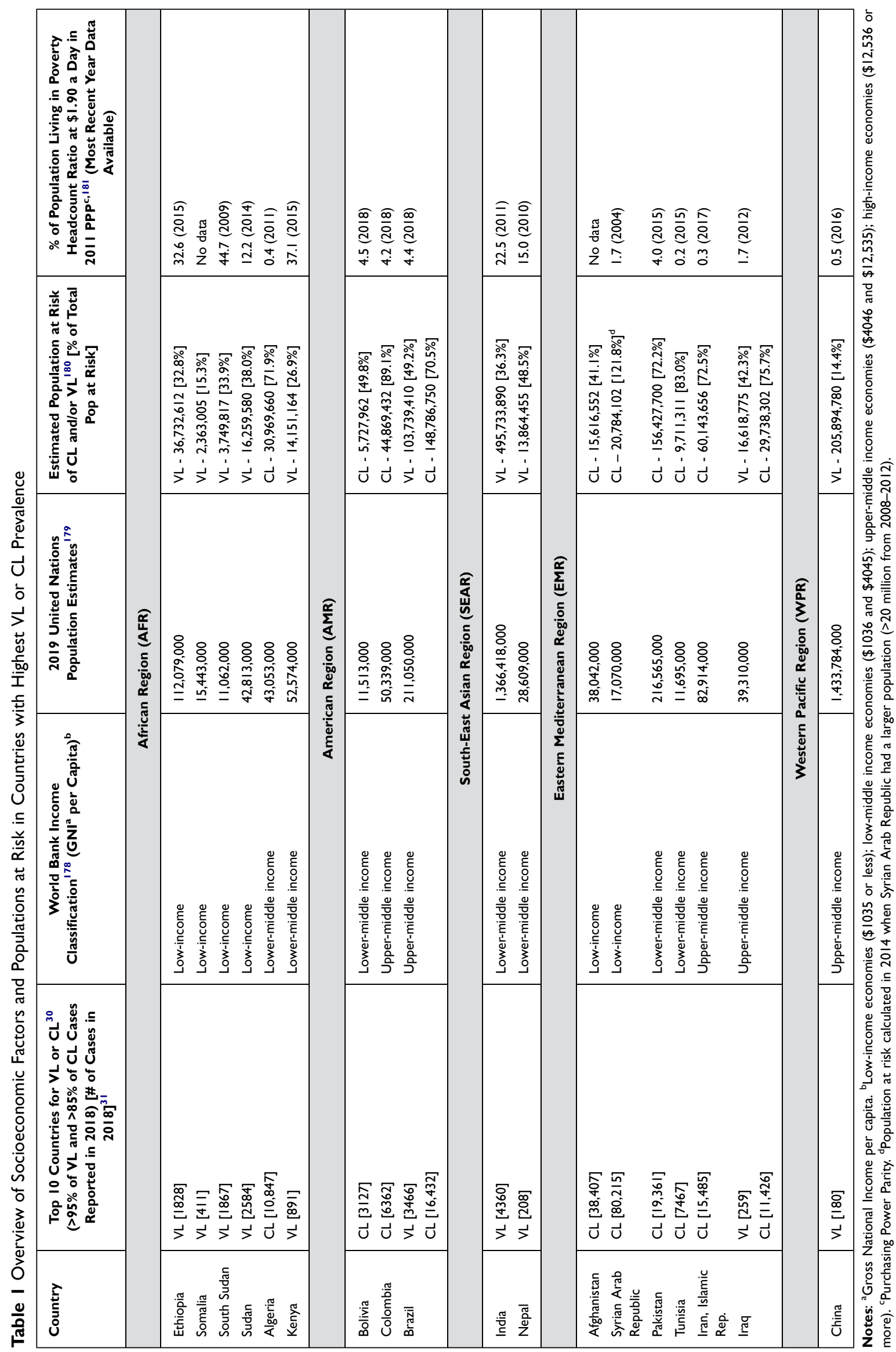


interventions in the decade to 2030 that are likely to have an intense focus on NTDs in general, thereby ending their "neglect."

\section{Vulnerability to and Risk Factors for Leishmaniases}

\section{Poverty, a Primary Risk Factor for the} Leishmaniases

Poverty is a central risk factor for the leishmaniases that is related to a complex network of exacerbating factors as outlined in Figure 1. Research shows that the leishmaniases primarily affect the poorest people on Earth and infections are associated with a lack of financial resources. ${ }^{30}$ Several studies have found low income to be a significant risk factor for $\mathrm{VL} .^{8,36,57,58}$ Low-economic household status adds multiple complexities to VL programming, such as: awareness, availability, access and adherence. ${ }^{15}$ For example, in India, those of the lowest caste disproportionately suffer from VL and have difficulty accessing care. ${ }^{11,59}$ Specifically, $83 \%$ of affected households belonged to the poorest $40 \%$ of the population. ${ }^{11}$ In
Kenya, Uganda, Ethiopia, Sudan and South Sudan, more VL cases are found among the poorest households. ${ }^{13,36,60}$ In Nepal, low economic status was found to be a significant risk factor for CL. ${ }^{20}$ Poverty led to a twofold increase in risk for CL in Iran and a 28-fold increase in risk in Sri Lanka. ${ }^{57}$

A systematic review of the socioeconomic risk factors of VL and CL in 2020 found that poverty is associated with inadequate housing and lack of sanitation, which foster continued incidence of leishmaniasis. ${ }^{57}$ Specifically, certain types of household construction materials create the optimal survival conditions for sandflies, which rest and breed in cracks or holes in walls and floors. Lack of adequate sanitation attracts wild or domestic animals and may be breeding sites for the sandflies. Examples include: Posadas, Argentina, where most individuals with VL also lived in low-quality homes composed of sand floors, wooden walls, partially or totally open roofs and without window screens; ${ }^{61}$ Bihar, India, where mudplastered walls increased the risk of VL two-fold compared to cement walls; ${ }^{62}$ and Fulbaria, Bangladesh, where the prevalence of VL was $59 \%$ in homes made with mud

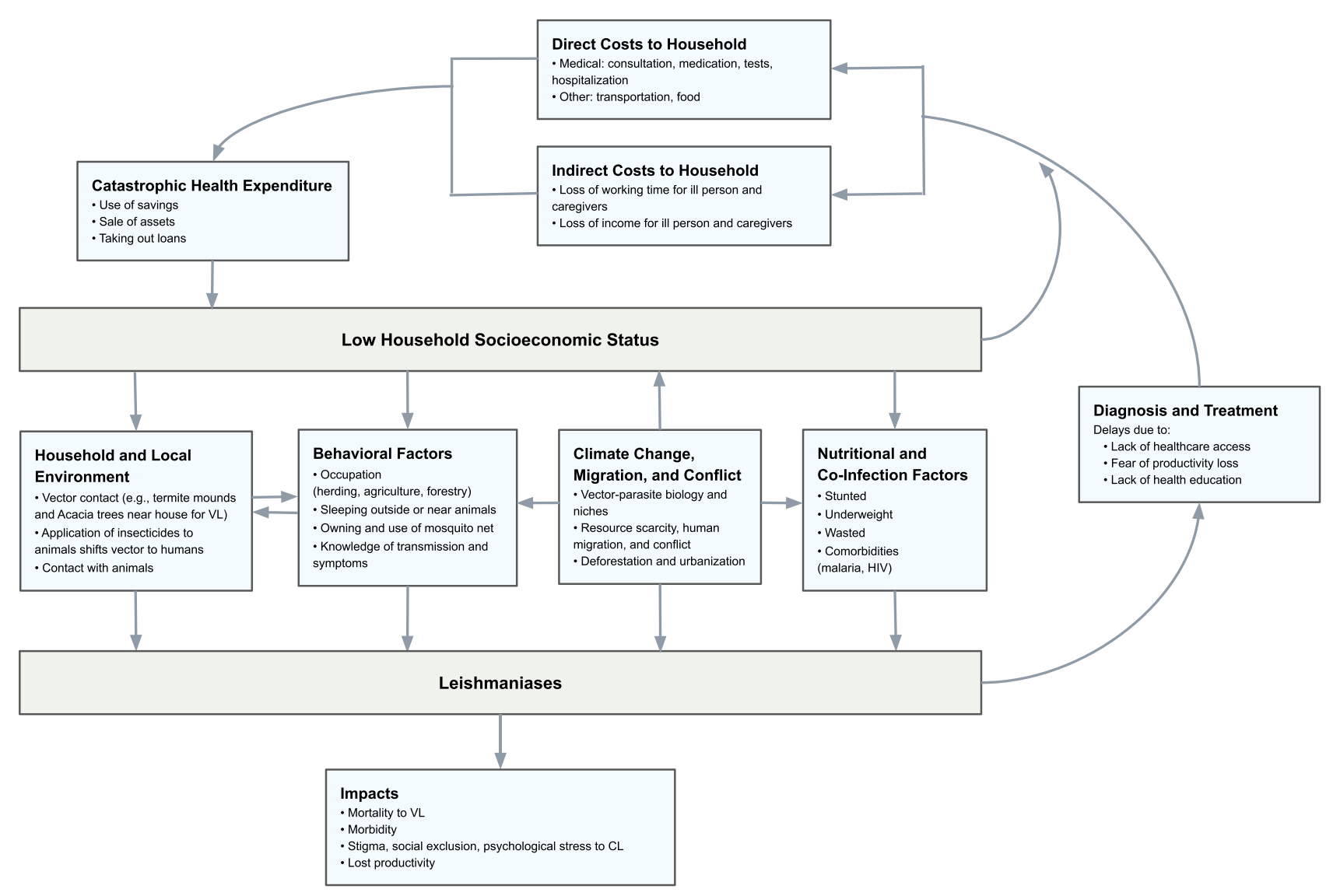

Figure I Framework of risk factors and impacts of the leishmaniases. 
floors and tin walls. ${ }^{63}$ Two studies in Brazil showed that a high incidence of VL was associated with a lack of appropriate sanitation and that low-income individuals resided in high-risk VL areas. ${ }^{7,8}$ Household characteristics were also found to be significant risk factors for CL: in Salta, Argentina, lack of locking windows increased the risk of CL almost three-fold; ${ }^{64}$ homes built with nondurable materials in Alagoas State, Brazil experienced a twofold increase in the risk of acquiring $\mathrm{CL} ;{ }^{65}$ and brick walls increased risk two-fold in Kabul, Afghanistan. ${ }^{66}$

Poor socioeconomic status exacerbates access to leishmaniasis services in other ways. With the onset of symptoms of VL, many patients avoid or delay seeking healthcare due to confusing symptoms with those of other diseases, gaps in VL awareness, disbelief in the severity of the condition, ${ }^{67,68}$ fear of loss of productivity, ${ }^{69}$ particularly if the afflicted family member is male, ${ }^{67,68}$ and cultural barriers where the decision to seek care for women and children has to be granted by the male head. ${ }^{70}$ Poor diet and low levels of education, all associated with poverty, are compounding risk factors for leishmaniasis. ${ }^{13}$ Lack of public health education on VL contributes to the morbidity of the disease. ${ }^{69,71}$ Many patients who are aware of VL and related symptoms may not seek care due to other factors, such as the absence of health facilities in remote areas, inability to afford transportation to health facilities and inability to afford appropriate diagnostics. ${ }^{15,67,72-74}$

Although many VL treatment programs are funded by government and donors, or some means of health-insurance is provided, ${ }^{15,17,75}$ direct and indirect medical costs push patients and their families further into poverty as a result of catastrophic health expenditure, ${ }^{76}$ promoting the cycle of poverty and disease. ${ }^{77}$ In many cases, VL treatment may require multiple days at health facilities, ${ }^{75,78}$ with financial burden falling on patients for each night spent in a hospital bed if these are not otherwise covered by a program. Prohibitive hospitalization costs could lead to an incomplete treatment regimen due to premature patient discharge. ${ }^{78}$ If treatment is administered at home, this accrues the direct overhead cost of a caregiver. ${ }^{69}$ On the other hand, costs may be indirect when a family member must relinquish labor responsibilities to care for the ill person. ${ }^{72}$ To pay for the devastating costs of treatment, studies show that households leverage four methods of coping: use of savings, sale or rental of property, taking private loans at high-interest rates and asking for financial help from their community. ${ }^{15,17,67,69,76}$ Due to this, the already impoverished, high-risk population falls into "iatrogenic poverty". 69

Additionally, poor populations often reside in remote areas far from health facilities, limiting timely access to treatment. Studies on travel time to healthcare facilities find that $8.9 \%$ of the global population cannot reach healthcare within one hour with access to motorized transport, while $43.3 \%$ cannot reach a healthcare facility within one hour by foot. ${ }^{74}$ The delay in healthcare-seeking is further exacerbated by the hope for self-resolution, which reduces quality of life, increases the development of chronic CL lesions, increases chances of VL mortality and increases the transmission of VL. ${ }^{67,72,74,79}$ Even with the use of peripheral testing sites and mobile clinics to reach remote areas, field clinicians lack the necessary equipment for diagnostic procedures, ${ }^{78,80}$ such as collecting spleen aspirates or bone marrow, ${ }^{81}$ making it difficult to diagnose VL. The use of rapid diagnostic tests, particularly rK39, can bridge this gap. ${ }^{17,69,82,83}$ However, in some countries where a six month follow-up appointment is required to confirm successful treatment, patients are not able to attend the final appointments. ${ }^{78,84,85}$

\section{Differential Leishmaniases Vulnerability and Impacts by Gender}

Not only do women account for the majority of the poor in what has been called "the feminization of poverty," but the financial impacts of the leishmaniases are experienced more significantly by women. ${ }^{67,86,87}$ The distribution of leishmaniases infections by gender is therefore helpful to understand the additional vulnerability women may face. ${ }^{36}$ While global data reporting on gender is incomplete, the latest WHO update shows substantial improvement between 2014 and 2018..$^{31}$ Globally, 63\% of VL patients were male and $34 \%$ were female. ${ }^{31}$ The majority of highburden countries had an over-representation of males, reaching up to $90 \%$ of cases in Ethiopia and $73 \%$ of cases in Nepal. ${ }^{31}$ Greater proportions of female VL cases were reported in two countries, namely Uganda (67\%) and Bangladesh (52\%). ${ }^{31}$ The distribution appears to be more balanced for CL, with $52 \%$ of cases male and $47 \%$ female. There is a slightly higher proportion of CL cases in males in the American region. ${ }^{31}$

A substantial amount of recent literature points to the vulnerability pathways and burden of leishmaniasis on women in particular. ${ }^{37,88-90}$ In some communities, women are at a higher risk for vector exposure if they 
spend more time in a home with livestock nearby or if they are tasked with responsibilities of animal care or procuring water, activities which typically occur in the morning or at dusk, which are times of heightened sandfly activity. ${ }^{88}$ The general deficiency of healthcare for women is also considered an important factor contributing to their vulnerability to leishmaniasis. ${ }^{88}$ Compared to men, women are less likely to seek healthcare in a timely manner when they have sought permission from their husbands, ${ }^{70}$ leading to more severe complications and, in the case of CL, a greater likelihood of life-long, disfiguring scarring. ${ }^{89}$ Late clinical presentations of women primarily stem from financial limitations and inadequate knowledge about the disease ${ }^{89}$ Furthermore, a lack of female healthcare providers is a significant barrier in places like Afghanistan, where women are often not allowed to visit male providers for cultural reasons. ${ }^{89}$ To afford treatment and avoid stigmatizing scars, women may sell their assets and suffer financially. ${ }^{88}$ The greater burden of disease and stigma limits the mobility of women and their capacity to work, affecting future economic opportunities. ${ }^{8,9}$ These findings suggest a need for research into interventions that target and minimize the specific vulnerabilities that place women at greater risk for the leishmaniases.

\section{Comorbidities Synergistically Act with Poverty to Exacerbate the Leishmaniases}

The leishmaniases co-occur with poverty in settings where populations also face immunocompromising conditions. Malnutrition and HIV infection are the most significant comorbidities because they increase host susceptibility, are determinants for severity and clinical manifestations of the leishmaniases, and complicate accurate diagnosis and treatment. ${ }^{25,85,91-93}$ For instance, case-controlled research in Ethiopia has shown a three-fold increase in susceptibility to VL in malnourished individuals. ${ }^{94,95}$ Additional research is needed to understand the impact of nutritional deficits on vector competence. ${ }^{93}$ Due to similar immunopathogenic processes, HIV significantly increases the risk of developing VL, while VL acts as a catalyst for HIV, thus accelerating the onset of AIDS. ${ }^{96,97}$ While undernutrition is an outcome of inadequate food compounded by poverty, the impoverished rural settings in which the leishmaniases largely occur are often co-endemic with other diseases, such as malaria, typhoid or typhus, tuberculosis and schistosomiasis, which make the diagnosis of VL complex due to the similarity in clinical manifestations. $^{25,30,98}$

Leishmania-HIV coinfection has been reported in at least 35 countries since first being reported in $1985 .{ }^{99}$ The Mediterranean basin accounted for the majority of VL-HIV coinfections in the 1990s, but East Africa now carries the majority of VL-HIV coinfections. ${ }^{31,91}$ Although the overall prevalence of HIV has been decreasing in African countries since the 2000s, ${ }^{100}$ prevalence of HIV amongst VL-infected individuals remains high. ${ }^{91}$ During 2014-2018, 2590 cases of new and relapsed VL-HIV coinfection were reported, with the prevalence of co-infection in VL patients increasing from $1.6 \%$ in 2014 to $3.8 \%$ in 2018 in four WHO regions (AFR, EMR, EUR, SEAR).$^{31}$ Ethiopia holds the highest burden of cases with up to $40 \%$ of VL patients positive for HIV. ${ }^{91}$ A potential factor contributing to high VL-HIV coinfection in northwest Ethiopia is the seasonal movement of cash-crop farmworkers, who become infected when traveling to VLendemic regions. ${ }^{13}$ High VL-HIV coinfection rates have also been reported in Brazil and the state of Bihar, India. ${ }^{30}$ In the Americas, $8 \%$ of VL cases were co-infected with HIV in 2017. Brazil carries $95 \%$ of these. ${ }^{102}$ VL co-infection can impact labor productivity as established in HIV studies, ${ }^{101}$ adding to cyclical poverty effects in these communities.

Atypical clinical manifestations of VL in people living with HIV complicate the deleterious relationship between these diseases, leading to delayed diagnosis and treatment. ${ }^{91}$ Although generally presenting as immunocompetent hosts, atypical signs and symptoms of VL (ie, splenomegaly, fever) may be confused for other opportunistic infections in the immunocompromised host. ${ }^{103}$ Leishmania parasites are also generally grouped by disease presentation of either CL or VL, but in patients with HIV, this tropism can be lost. ${ }^{104}$ For example, parasites that classically cause CL may cause visceralization and patients with VL may have skin lesions. ${ }^{104}$ Additionally, atypical cases may be missed and underreported in resource-poor settings using disease detection guidelines strictly based on clinical case definitions. ${ }^{91}$ VL-HIV coinfected patients may also present with amastigotes at unusual sites, such as the gastrointestinal tract. ${ }^{96}$ Misdiagnosis leads to an increased case fatality rate. ${ }^{99}$

Comorbid HIV also leads to poor diagnostics outcomes and therapeutic response. Parasitological methods remain the gold standard for diagnosis due to the low sensitivity of serological tests in detecting VL in HIV-infected individuals. ${ }^{96}$ Given the prevalence of relapse in this population, the use of polymerase chain reaction (PCR) testing 
to identify circulating Leishmania DNA can indicate imminent VL relapse. ${ }^{105}$ Initiation of antiretroviral therapy (ART) can delay VL relapses and reduce mortality, in combination with secondary prophylaxis. ${ }^{85,96}$ However, the lack of access and suboptimal adherence to ART, drug toxicity from combined treatment and expense remain as barriers to care. ${ }^{97,106}$ Recommended drug combinations for VL-HIV treatment also vary based on location, which complicates access and monitoring treatment outcomes. ${ }^{97,106}$ Research on CL-HIV coinfection remains scarce and current treatment guidelines are based on immunocompetent individuals. ${ }^{106}$ Like PKDL patients, coinfected patients can act as human reservoirs for the Leishmania parasites, perpetuating sandfly infection rates in communities. ${ }^{97,107,108}$ A comprehensive survey of the variable presentations of the leishmaniases in co-infected patients would provide useful diagnostic information for clinicians who may see a growing number of these complex medical cases.

\section{Environment, Migration, Conflict and Climate Change Exacerbate Vulnerability to the Leishmaniases}

Aside from being associated with impoverished environments, the leishmaniases occur in certain ecoepidemiological foci that reflect manipulation by human activities, such as migration, urbanization and deforestation. $^{25}$ Poverty and conflict are key drivers of population displacement and forced migration among the poor. ${ }^{109}$ These drivers have led to the catastrophic expansion of CL, especially in North Africa and the Middle East. ${ }^{110,111}$ In the Indian sub-continent, elimination is hindered by cross-border movements; ${ }^{112}$ in Eastern Africa, control is complicated by both migration, conflict and a changing climate (Figure 1). ${ }^{14,60,113}$ The intersection of climate change and the leishmaniases adds other complexities, as it is a multi-faceted process entangled with other socioeconomic drivers and impacts of the disease. As both a lever for exacerbating the existing inequalities that drive leishmaniasis risk and as a risk factor in and of itself, climate change will likely introduce new disease foci and further impoverish at-risk communities. ${ }^{114}$ While climate change will affect everyone, the most vulnerable - poor communities without the capacity to develop resilient infrastructure - are most at risk of the compounding economic disaster driven by climate change and disease. ${ }^{115}$ Discussed here are several mechanisms through which climate change is thought to drive leishmaniasis risk, including: interactions between vector-parasite biology and temperature, human migration, and conflict.

There is evidence that the pace of human migration for economic reasons or because of conflict is exacerbated by climate change. ${ }^{116-118}$ The accelerating international movement of people and goods has increased the likelihood that Leishmania parasites may gain a foothold in unafflicted countries where a stable vector and reservoir population is already present. ${ }^{119}$ During 2017-2018, estimated 1882 cases of CL and 141 cases of VL globally were caused by transnational migration and importation, creating opportunities for parasites to establish footholds in non-endemic regions with competent vectors. ${ }^{31}$ Urbanization also provides opportunities for the introduction of the leishmaniases to previously unafflicted niches. In Brazil, an increasing number of cases are seen in urban centers, rather than in the traditionally endemic rural regions, due in part to urbanization and internal migration of peoples from rural communities into peri-urban centers with poor sanitation. ${ }^{120}$ Driven by migration and climate change, recent case reports from Eritrea, Kenya, and Tanzania have demonstrated that the territories in which autochthonous leishmaniases occur are expanding. ${ }^{121-123}$ Additionally, deforestation and changing patterns of land use for agriculture provide new ecological niches for sandflies. $^{124,125}$ Local agriculture, an important source of calories and nutrients for poor communities, is additionally threatened by climate change as rising $\mathrm{CO}_{2}$ levels contribute to nutrient leaching. ${ }^{126,127}$ Thus, as farmers are put at greater risk of infection through agricultural practices that provide opportunities for sandflies to spread, the risk is exacerbated through the loss of nutritional value within the food produced.

As shown in studies in the Middle East, North Africa and Eastern Africa, ${ }^{14,60,110,111,113}$ conflict drives the spread of the leishmaniases in multiple ways, some of which intersect with patterns of human migration. While climate change is not the exclusive driver of violent conflict, climate change and resulting resource scarcity will likely contribute to many conflicts in the coming decades when additional destabilizing factors are in place. ${ }^{128}$ The breakdown of health systems during conflicts, including drug delivery, clinician training, availability of diagnostics, and health systems financing and reporting, pose great risks to leishmaniasis control in endemic countries and perpetuate its status as a neglected disease. This process was exemplified by the conflict in Sudan which began in the 1980s 
and the subsequent leishmaniasis outbreaks which resulted in approximately 100,000 deaths. ${ }^{14,129-131}$ Refugees from conflict zones in endemic regions of the Middle East can carry new species of Leishmania parasites into territories where transmission is possible due to the presence of appropriate vectors, ${ }^{132-134}$ and the breakdown of treatment and care for patients can result in more serious disease progressions with a greater likelihood for complications and stigmatizing disfigurement. ${ }^{135}$

Several mechanisms through which climate change is thought to drive leishmaniasis risk include interactions between vector-parasite biology and temperature, human migration and conflicts intensified by climate change. Ostfeld and Keesing describe how arthropods, such as the vector for leishmaniasis, the Phlebotomine and Lutzomyia sandflies, increase the rate of metabolic activity under warmer conditions, increasing the risk of disease for those within endemic regions and introducing risk to warming climates where sandflies can newly thrive. ${ }^{136}$ Studies of both vector and parasite biology have demonstrated a positive relationship between metabolic activity and temperature. ${ }^{137}$ Climate models in Europe and the Americas have predicted the northward expansion of the sandfly's territory, ${ }^{138,139}$ and recent entomological surveys of sandfly distribution in Europe suggest the introduction of Leishmania competent vectors into new regions. ${ }^{140-142}$ The territorial expansion of these vectors heightens the need for clinician and public awareness, appropriate public health intervention and continued monitoring as the climate continues to change.

The complex relationship between climate change, conflicts, migration and the leishmaniases requires nuanced models that account for more than the direct effects of warming surface temperatures. Consideration of the human response to climate change, the local and national socioeconomic contexts in which climate policy will be enacted and the relationship between the leishmaniases and other disorders, such as malnutrition, are critical for understanding the changing geography and burden of disease.

\section{Socioeconomic Impacts of the Leishmaniases}

To better understand the various economic impacts of the leishmaniases, we disentangle them by types of costs (direct and indirect costs) incurred by households and healthcare systems.

\section{Types of Costs Incurred}

Visceral Leishmaniasis

Although treatment for VL varies by drug combination and by patient, the regimen requires several (up to 30) days of daily injections. In many cases, patients are hospitalized for the duration of treatment with significant cost implications. ${ }^{25,78}$ As such, significant direct and indirect costs can be incurred by the patient and program, as several studies show. A systematic review using 2016 US dollars found that the median total direct cost per treated patient was \$760 in Sudan, \$128 in Nepal, \$197 in India, and \$220 in Bangladesh. ${ }^{23}$ Direct medical costs were most common in the care-seeking phase and direct non-medical costs, such as food and transportation, were higher during treatment. ${ }^{23}$ Direct medical costs varied based on the type of provider visited (traditional healers, chemists or pharmacists, clinics, hospitals) and the type and source of administered VL treatment. ${ }^{23}$ Other studies have identified food as a significant direct non-medical cost for patients and caretakers throughout the treatment period. ${ }^{21,77}$ Indirect costs have been reported as working days lost for patients and/or caretakers or as loss of wages: ${ }^{23}$ Patients and household members lost 57 days of productivity in Nepal, ${ }^{20,69}, 120$ days were lost amongst the economically active in India ${ }^{143}$ and 51 days of productivity were lost among patients in Sudan. ${ }^{144}$

\section{Cutaneous Leishmaniasis/Post-Kala-Azar Dermal Leishmaniasis}

To the best of our knowledge, there has not been a comprehensive, multi-country review of the types of costs incurred during diagnosis and treatment of $\mathrm{CL}$ and PKDL. We identified singular studies in Iran, Sri Lanka, and Brazil. In the Iranian Province of Golestan in 2015, CL patients spent an average of $\$ 129$ (43\% direct medical costs, $20 \%$ direct non-medical costs, and $37 \%$ indirect costs). ${ }^{145}$ A 2017 cross-sectional study of all 31 provinces in Iran found that the out-of-pocket (OOP) payments per patient was $\$ 7 .{ }^{146}$ In Sri Lanka, the total median cost per patient (both direct and indirect) was $\$ 67 .{ }^{147}$ This study reported that $59 \%$ of patients traveled over 100 kilometers to receive treatment, which resulted in a loss of income for both the patient and the person traveling with them. A 2017 cross-sectional study in Brazil found the total medical costs to CL patients was $\$ 125 .{ }^{148}$ Top contributors to direct medical costs included medications (17\%), medical appointments (15\%), medical exams $(9 \%)$ and health insurance costs $(10 \%)$. Top contributors to direct non- 
medical costs were transportation to health centers $(26 \%)$ and food (8\%). ${ }^{148}$

Only one study of the economic impact of PKDL was found. ${ }^{19}$ In Bangladesh, the mean total direct cost per treated patient was $\$ 179 .{ }^{19}$ The major contributors to this cost were food (largest), treatment and transportation costs. Indirect cost measured was the asset loss per patient (median of \$170) and lost days of work (median of 43 days) ${ }^{19}$

\section{Catastrophic Health Expenditure}

The impact of OOP payments is difficult to conceptualize, since costs of living and income vary drastically between studied populations. Thus, looking at this data in the context of catastrophic health expenditure (CHE) is necessary. $\mathrm{CHE}$ is defined as the cost of health services that divert money from supporting basic household needs or cause households to resort to using their savings. ${ }^{76,149} \mathrm{CHE}$ ranges from $5 \%$ to $15 \%$ of total household income, with exact values depending on the study. Several studies have examined CHE for VL, CL and PKDL in multiple countries.

\section{Visceral Leishmaniasis}

A systematic review found that if a $10 \%$ threshold is used to measure CHE, then VL imposes heavy financial burdens on households. ${ }^{23}$ The percentage of household income diverted to $\mathrm{VL}$ treatment ranged from $11 \%$ to $44 \%$ in Nepal, $21-37 \%$ in India and was $21 \%$ in Bangladesh. ${ }^{23}$ In Sudan, $40 \%$ of household income was diverted to VL treatment. ${ }^{21}$ One study in Nepal found that $51 \%$ of households made payments exceeding the $10 \%$ CHE threshold and that the cost of VL treatment was equal to $57 \%$ of the median per capita income. ${ }^{20}$ Had the medications not been free of cost, $74 \%$ of households would have exceeded the $10 \%$ CHE mark. ${ }^{20}$ Another study in Nepal found the median cost per household diagnosed with more than one case of VL was $\$ 425$, which is greater than the median annual household income of $\$ 405 .{ }^{69}$ In other studies, it was found that the cost associated with VL forced $20 \%$ of families in Nepal below the poverty line. ${ }^{150,151}$ In rural Bihar, India, VL treatment costs the equivalent of 7 months of daily wages. ${ }^{143} \mathrm{In}$ Bangladesh, India, Nepal and Sudan, 25-75\% of affected households experienced some form of financial catastrophe throughout diagnosis and treatment, despite the free provision of tests and medication. ${ }^{17-21}$

\section{Cutaneous Leishmaniasis/Post-Kala-Azar Dermal Leishmaniasis}

CHE data for CL and PKDL are more limited and no systematic analyses have been identified. We identified singular studies in Sri Lanka, Brazil and Bangladesh. In Sri Lanka, the $\$ 67$ total cost of CL treatment accounted for $5.4 \%$ of annual household income and $21 \%$ of the mean annual per capita income, ${ }^{147}$ both of which could qualify as CHE depending on the threshold used. In this study, $57 \%$ of the patients identified as the only household member contributing to income. ${ }^{147}$ In Brazil, $50 \%$ of study participants paid an average of $22 \%$ of their household income for CL-related costs. ${ }^{148}$ In Bangladesh, the median total household cost per patient for PKDL treatment was $\$ 367$, which was more than twice the per capita annual income of the studied population. ${ }^{19}$

\section{Costs from the Healthcare System Perspective Visceral Leishmaniasis}

Costs from the healthcare system perspective in diagnosis and treatment for VL have been analyzed in Morocco, Brazil, India, and Sudan. In a seven-hospital study in Morocco that analyzed 127 records of VL patients, it was found that the median cost to the health provider was $\$ 520$ per VL patient, which comprised: $50 \%$ came from hospitalization, $15 \%$ diagnosis and treatment and 33\% drug costs or tests not related to VL. ${ }^{152}$ Indirect costs were not measured. When care was provided at an outpatient facility, costs were significantly reduced (\$307 vs \$636). ${ }^{152}$ A study in Brazil found direct costs varied based on which drugs were used for treatment and which route they were administered (intramuscular vs intravenous). ${ }^{153}$ A 2014 study in Brazil measured direct medical costs and found that the total VL medical direct costs to the institution were $\$ 1,873,682$, which comprised: $41 \%$ hospital and ambulatory care, $22 \%$ treatment, $18 \%$ diagnostics and $18 \%$ from VL/HIV secondary prophylaxis. ${ }^{154}$ A retrospective review of 250 medical records from 2008 from three public hospitals in Sudan showed that the medical cost per patient varied between $\$ 117$ and $\$ 366$, depending on the hospital. ${ }^{21}$

\section{Cutaneous Leishmaniasis/Post-Kala-Azar Dermal} Leishmaniasis

Individual studies for CL were identified in Iran, Afghanistan and Sri Lanka. A 2017 cross-sectional study of the economic burden of CL in 31 provinces in Iran found that costs to the government health systems associated with diagnosis and treatment of CL were high: 
nearly $\$ 6$ million over the study period. ${ }^{146}$ Elements of governmental costs included salaries to health-care providers $(15 \%$ of total cost), medical materials and devices used (drug purchase, syringes, cotton, etc.) (37\%), building depreciation and physical space costs (14\%), administrative, health and treatment facilities cost (6\%) and urban amenities (28\%). ${ }^{146}$ A 2010 study in Kabul, Afghanistan, found that costs varied based on drug used and route delivered. ${ }^{155}$ In Sri Lanka, the total median cost per patient to the provider was $\$ 23 .{ }^{147}$ No studies were found on PKDL.

Overall, there is a need for new studies to be conducted to examine the economic impacts of the leishmaniases in endemic regions since the majority of studies are dated. Most published studies have focused on VL and CL, so there is a serious need for studies examining the economic impacts of PKDL. Lastly, it is difficult to compare costing studies due to differences in definitions of costs and the methods used to measure and quantify those costs. A uniform approach to costing methodology is essential for future studies.

\section{Psychosocial Impacts of the Leishmaniases}

Leishmaniasis may result in profound psychological and social burdens due to reduced quality of life (QoL), social exclusion and poor mental health. ${ }^{3}$ Physical impairments and disfigurements, primarily observed in the dermatological presentations of CL and PKDL, lead to stigmatization, discrimination and ultimately psychosocial impact (Figure 1). ${ }^{38}$

The psychosocial burden of CL has been well documented in the literature, with an estimated $70 \%$ of all $\mathrm{CL}$ cases (active and inactive) experiencing some degree of psychological morbidity, generally depending on the severity and visibility of disfigurement. ${ }^{37,156}$ Individuals with CL are restricted from social participation, affecting their community interactions and personal relationships. ${ }^{157}$ Misconceptions about disease transmission fuel stigma and discrimination, as many societies erroneously believe CL to be directly contagious through person-to-person physical contact. ${ }^{37}$ For example, studies in Afghanistan reported that women with $\mathrm{CL}$ are often separated from their children and prevented from breastfeeding, leading to depression and anxiety. ${ }^{158,159}$ Social exclusion and resulting isolation induce internalized self-stigma and decreased self-esteem, which in turn contribute to psychological manifestations of stress, anxiety and depression. ${ }^{37}$ Studies in Iran and Turkey have revealed significantly decreased body satisfaction and $\mathrm{QoL}$ in $\mathrm{CL}$ patients. $^{35,160,161}$ Severe self-isolation and self-contempt may sometimes even contribute to suicidal ideations. ${ }^{37}$ Stigma further hinders treatment-seeking behavior due to the shame of being seen in public, which may exacerbate health outcomes. ${ }^{157}$ These psychosocial impacts often influence educational and employment opportunities. ${ }^{157}$

The greatest psychosocial burden of CL is experienced by young, single women, particularly those with visible facial scars. ${ }^{37,90,162}$ As shown in the 2018 global data, $47 \%$ of CL cases are women. ${ }^{31} \mathrm{CL}$ lesions generally occur on visible parts of the body, such as the face or hands, due to opportunistic sandfly bites on exposed skin. ${ }^{157}$ Women consistently report that such lesions alter the perception of beauty and cause negative body image, which has a significant impact on marriage opportunities. ${ }^{37}$ Furthermore, women tend to be less likely than men to seek treatment promptly, often due to limited healthcare accessibility or cultural barriers. ${ }^{88}$ Untimely treatment results in life-long scarring and women may suffer financially in attempts to afford basic treatments or permanent surgical solutions. ${ }^{37,88}$

A systematic review examining psychosocial well-being for all forms of leishmaniasis revealed substantial gaps in the literature for VL and MCL in particular. ${ }^{38}$ While VL has been shown to decrease the QoL of patients, this review calls for more research to explore how neurological manifestations of VL may potentially relate to psychological impacts. ${ }^{38}$ Additionally, stigma has been reported among patients co-infected with VL and HIV, significantly affecting QoL. ${ }^{163,164}$ PKDL, a dermatological consequence of VL characterized by visible rash and disfigurement, has been associated with poor mental health and impaired QoL due to social stigma and exclusion. ${ }^{165,166}$ Stigmatization further impacts PKDL and VL-HIV outcomes by influencing treatment-seeking behavior and drug compliance. ${ }^{165,166}$

Following these findings, leishmaniasis programs are encouraged to broaden in scope to include mental health support and community educational interventions to address the growing psychosocial burden. ${ }^{167}$ This approach was endorsed by the WHO, which recently published its first guide on the mental health of people with NTDs, highlighting the negative impacts of NTD-related stigma on psychosocial well-being and treatment-seeking behavior. ${ }^{168}$ Further studies of the psychosocial impact of leishmaniasis could focus on the bidirectional relationship 
between stigma and poverty. Recognition of the complex network between poverty, health and social exclusion would provide a more complete picture of the psychosocial impacts of the leishmaniases.

\section{Discussion and Conclusion}

The literature on the socioeconomic and psychosocial impacts of the leishmaniases, vulnerability and risk factors are wideranging. In general, much research has been done on the disease relative to disease burden and other NTDs. ${ }^{169}$ However, a full accounting of their various impacts is lacking. Here we have reviewed a large body of literature to try to fill in the gap. Overall, it is difficult to compare costing studies due to differences in definitions of costs and methods to measure and quantify those costs. There is a need for a uniform approach to costing methodology to ensure all appropriate variables are accounted for and collected in the same manner so comparisons can be made between countries where culture and disease factors differ. In addition, the majority of studies identified in our analysis are retrospective or cross-sectional with limited timeframes. Longitudinal studies could provide additional information on the impact of the leishmaniases (both direct and indirect) on individuals and their households long term, the impact of various financial coping strategies and the impact on poverty and health systems. ${ }^{78,170}$ Such longitudinal studies should be developed in the context of national and international improvements to leishmaniasis data collection and reporting, a need emphasized by the discrepancies between predicted and observed leishmaniasis cases reported by the WHO. ${ }^{30,31}$

As this review shows, financial barriers preventing diagnosis and treatment of leishmaniasis must be reduced in the pursuit of universal health coverage, a key target of the SDGs and the 2030 NTDs Roadmap. ${ }^{45,49}$ Mechanisms such as transporting patients early to treatment centers, the introduction of peripheral testing sites, community healthcare workers, telemedicine and use of mobile clinics can simplify access to care, eliminate costs and facilitate early detection of rural patients to drive elimination of VL. ${ }^{15,71,73,74,170}$ In addition, less expensive diagnostic and treatment measures must continue to be developed, as demonstrated by the introduction of rK39 leading to dramatic increases in the ability to diagnose rural populations. ${ }^{73,88,171}$

An evaluation of the various socioeconomic costs of the leishmaniases would not be complete without an understanding of the socioeconomic losses averted by improving leishmaniasis care. Using data collected in a systematic literature review, Lenk et al identified the economic benefit from averted OOP payments and averted productivity loss by calculating the difference between a "counterfactual scenario," which assumed the $1990 \mathrm{VL}$ prevalence/incidence continued uninterrupted, and an "ideal scenario," which assumed the 2020 targets described by the 2012 London Declaration and the WHO were achieved. ${ }^{172}$ In 2005 \$US, the total economic benefit from OOP payments averted was calculated to be $\$ 100$ million from 1990 to 2030. The total economic benefit from productivity loss averted was $\$ 70$ million from 2011 to 2030 . When deaths are taken into account, the productivity loss averted rises to $\$ 7.2$ billion from 2011 to $2020 .^{172}$ This study shows there is a clear long-term benefit to early detection and effective treatment of VL, and other researchers have determined these are cost-effective. ${ }^{173}$ While we found no similar studies that have been conducted for CL and PKDL, we believe such would be needed for a full accounting of the costs of the leishmaniases.

Understanding the economic consequences of leishmaniasis and the benefits of treatment on a global scale will encourage prevention, while also assuring policymakers and donors that the monetary resources directed to leishmaniasis control and elimination are a good investment. $^{22,23,58}$ This is especially important as most programming is financed by donors whose operations have been dramatically hindered by the COVID-19 pandemic that will impact present and future NTD work. $^{52-55,174}$ Additionally, competing priorities in global health across diseases and programs accompanied by limited resources ${ }^{175,176}$ justifies a call to leverage opportunities to integrate efforts to combat the leishmaniases with other diseases, such as HIV and malaria, that have more funding. ${ }^{176,177}$ In light of the long-term severe disfigurement from CL leading to stigmatization, social exclusion, discrimination and psychosocial impacts, especially on rural women, which negatively affect social and economic opportunities, integrating mental health support and community educational interventions as the WHO has championed is warranted. ${ }^{168}$

The world faces worrying trends in human migration coupled with climate change and conflict that compound global and national phenomena that introduce new vulnerabilities within communities at risk for the leishmaniases and produce new opportunities for the disease to spread. $4,118,129$ Without mitigation efforts on all of these aspects, the 1.7 billion at risk of the leishmaniases could increase. Elimination of the leishmaniases is possible. The NTDs Roadmap to 2030 and the 2030 SDG framework 
offer unprecedented opportunities to mitigate the cyclical and synergistic socioeconomic and psychosocial impacts of the leishmaniases shown in this review.

\section{Disclosure}

All authors report no conflicts of interest in this work.

\section{References}

1. Alonso LM, Alvar J. Stigmatizing neglected tropical diseases: a systematic review. Soc Med. 2010;5(4).

2. Esch KJ, Petersen CA. Transmission and epidemiology of zoonotic protozoal diseases of companion animals. Clin Microbiol Rev. 2013;26(1):58-85.

3. Hofstraat K, van Brakel WH. Social stigma towards neglected tropical diseases: a systematic review. Int Health. 2016;8(Suppl 1):i53-70. doi:10.1093/inthealth/ihv071

4. Mitra A, Mawson A. Neglected tropical diseases: epidemiology and global burden. Trop Med Infect Dis. 2017;2(3):36.

5. World Health Organization. Control of neglected tropical diseases. Geneva: World Health Organization; 2021. Available from: https://www.who.int/teams/control-of-neglected-tropicaldiseases. Accessed March, 42021.

6. World Health Organization and NICEF/UNDP/World Bank/WHO Special Programme for Research and Training in Tropical Diseases. Global Report for Research on Infectious Diseases of Poverty 2012. Geneva: World Health Organization; 2012.

7. Hotez PJ. Blue Marble Health. Baltimore: Johns Hopkins University Press; 2016.

8. Bern C, Courtenay O, Alvar J, Boelaert M. Of cattle, sand flies and men: a systematic review of risk factor analyses for South Asian visceral leishmaniasis and implications for elimination. PLoS Negl Trop Dis. 2010;4(2):e599. doi:10.1371/journal. pntd.0000599

9. Malafaia G. Protein-energy malnutrition as a risk factor for visceral leishmaniasis: a review. Parasite Immunol. 2009;31 (10):587-596. doi:10.1111/j.1365-3024.2009.01117.x

10. Herrero M, Orfanos G, Argaw D, et al. Natural history of a visceral leishmaniasis outbreak in highland Ethiopia. $\mathrm{Am}$ $J$ Trop Med Hyg. 2009;81(3):373-377. doi:10.4269/ ajtmh.2009.81.373

11. Boelaert M, Meheus F, Sanchez A, et al. The poorest of the poor: a poverty appraisal of households affected by visceral leishmaniasis in Bihar, India. Trop Med Int Health. 2009;14(6):639-644. doi:10.1111/j.1365-3156.2009.02279.x

12. Zeilhofer P, Kummer OP, Santos ESD, Ribeiro ALM, Missawa NA. Spatial modelling of Lutzomyia (Nyssomyia) whitmani s.l. (Antunes \& Coutinho, 1939) (Diptera: psychodidae: phlebotominae) habitat suitability in the state of Mato Grosso, Brazil. Memórias Do Instituto Oswaldo Cruz. 2008;103 (7):653-660. doi:10.1590/S0074-02762008000700005

13. Argaw D, Mulugeta A, Herrero M, et al. Risk factors for visceral Leishmaniasis among residents and migrants in Kafta-Humera, Ethiopia. PLoS Negl Trop Dis. 2013;7(11):e2543. doi:10.1371/ journal.pntd.0002543

14. Al-Salem W, Herricks JR, Hotez PJ. A review of visceral leishmaniasis during the conflict in South Sudan and the consequences for East African countries. Parasit Vectors. 2016;9(1):460. doi:10.1186/s13071-016-1743-7

15. DebRoy S, Prosper O, Mishoe A, Mubayi A. Challenges in modeling complexity of neglected tropical diseases: a review of dynamics of visceral leishmaniasis in resource limited settings. Emerg Themes Epidemiol. 2017;14:10. doi:10.1186/s12982-0170065-3
16. Lemma W, Tekie H, Yared S, et al. Sero-prevalence of Leishmania donovani infection in labour migrants and entomological risk factors in extra-domestic habitats of Kafta-Humera lowlands - kala-azar endemic areas in the northwest Ethiopia. BMC Infect Dis. 2015;15(1):99. doi:10.1186/s12879-015-0830-2

17. Anoopa Sharma D, Bern C, Varghese B, et al. The economic impact of visceral leishmaniasis on households in Bangladesh. Trop Med Int Health. 2006;11(5):757-764. doi:10.1111/j.13653156.2006.01604.x

18. Sundar S, Arora R, Singh SP, Boelaert M, Varghese B. Household cost-of-illness of visceral leishmaniasis in Bihar, India. Trop Med Int Health. 2010;15(Suppl 2):50-54. doi:10.1111/j.13653156.2010.02520.x

19. Ozaki M, Islam S, Rahman KM, Rahman A, Luby SP, Bern C. Economic consequences of post-kala-azar dermal leishmaniasis in a rural Bangladeshi community. Am J Trop Med Hyg. 2011;85 (3):528-534. doi:10.4269/ajtmh.2011.10-0683

20. Uranw S, Meheus F, Baltussen R, Rijal S, Boelaert M. The household costs of visceral leishmaniasis care in South-eastern Nepal. PLoS Negl Trop Dis. 2013;7(2):e2062. doi:10.1371/journal.pntd.0002062

21. Meheus F, Abuzaid AA, Baltussen R, et al. The economic burden of visceral leishmaniasis in Sudan: an assessment of provider and household costs. Am J Trop Med Hyg. 2013;89(6):1146-1153. doi:10.4269/ajtmh.12-0585

22. Fitzpatrick C, Nwankwo U, Lenk E, de Vlas SJ, Bundy DAP. An investment case for ending neglected tropical diseases. In: Disease Control Priorities. Vol. 6. Third edition. The World Bank; 2017:411-431.

23. Sunyoto T, Boelaert M, Meheus F. Understanding the economic impact of leishmaniasis on households in endemic countries: a systematic review. Expert Rev Anti Infect Ther. 2019;17 (1):57-69. doi:10.1080/14787210.2019.1555471

24. Marinho DS, Casas CNPR, Pereira CCDA, Leite IC, Lee BY. Health economic evaluations of visceral leishmaniasis treatments: a systematic review. PLOS Negl Trop Dis. 2015;9(2):e0003527. doi:10.1371/journal.pntd.0003527

25. World Health Organization Expert Committee on the Control of Leishmaniasis and World Health Organization. Control of the Leishmaniases: Report of a Meeting of the WHO Expert Committee on the Control of Leishmaniases. Geneva: World Health Organization; 2010.

26. Dedet JP, Pratlong F. Leishmaniasis. In: Manson P, Cook C, Zumla A, editors. Manson's Tropical Diseases. London: Saunders; 2003:1339-1364.

27. Hong A, Zampieri RA, Shaw JJ, Floeter-Winter LM, LaranjeiraSilva MF. One health approach to leishmaniases: understanding the disease dynamics through diagnostic tools. Pathogens. 2020;9 (10):809. doi:10.3390/pathogens9100809

28. Lewis DJ. Phlebotomid sandflies. Bull World Health Organ. 1971;44(4):535-551.

29. Pigott DM, Bhatt S, Golding N, et al. Global distribution maps of the leishmaniases. eLife. 2014;3. doi:10.7554/eLife.02851

30. World Health Organization. Leishmaniasis. Geneva: World Health Organization; 2020. Available from: https://www.who.int/news-room /fact-sheets/detail/leishmaniasis. Accessed February 24, 2021.

31. Ruiz-Postigo JA, Grout L, Jain S. Global leishmaniasis surveillance, 2017-2018, and first report on 5 additional indicators. Wkly Epidemiolog Record. 2020.

32. Wamai RG, Kahn J, McGloin J, Ziaggi G. Visceral leishmaniasis: a global overview. J Glob Health Sci. 2020;2(1). doi:10.35500/ jghs.2020.2.e3

33. Zijlstra EE, Musa AM, Khalil EA, el-Hassan IM, el-Hassan AM. Post-kala-azar dermal leishmaniasis. Lancet Infect Dis. 2003;3 (2):87-98. doi:10.1016/S1473-3099(03)00517-6 
34. Mukhopadhyay D, Dalton JE, Kaye PM, Chatterjee M. Post kala-azar dermal leishmaniasis: an unresolved mystery. Trends Parasitol. 2014;30(2):65-74. doi:10.1016/j.pt.2013.12.004

35. Yanik M, Gurel MS, Simsek Z, Kati M. The psychological impact of cutaneous leishmaniasis. Clin Exp Dermatol. 2004;29 (5):464-467. doi:10.1111/j.1365-2230.2004.01605.x

36. Okwor I, Uzonna J. Social and economic burden of human leishmaniasis. Am J Trop Med Hyg. 2016;94(3):489-493. doi:10.4269/ajtmh.15-0408

37. Bennis I, De Brouwere V, Belrhiti Z, Sahibi H, Boelaert M. Psychosocial burden of localised cutaneous Leishmaniasis: a scoping review. BMC Public Health. 2018;18(1):358. doi:10.1186/s12889-018-5260-9

38. Pires M, Wright B, Kaye PM, Da Conceição V, Churchill RC, Picado A. The impact of leishmaniasis on mental health and psychosocial well-being: a systematic review. PLoS One. 2019;14(10):e0223313. doi:10.1371/journal.pone.0223313

39. Boukthir A, Bettaieb J, Erber AC, et al. Psycho-social impacts, experiences and perspectives of patients with Cutaneous Leishmaniasis regarding treatment options and case management: an exploratory qualitative study in Tunisia. PLoS One. 2020;15 (12):e0242494. doi:10.1371/journal.pone.0242494

40. Hotez PJ, Alvarado M, Basáñez M-G, et al. The global burden of disease study 2010: interpretation and implications for the neglected tropical diseases. PLoS Negl Trop Dis. 2014;8(7): e2865. doi:10.1371/journal.pntd.0002865

41. Global Burden of Disease. 2017 DALYs and HALE Collaborators. Global, regional, and national disability-adjusted life-years (DALYs) for 359 diseases and injuries and healthy life expectancy (HALE) for 195 countries and territories, 1990-2017: a systematic analysis for the Global Burden of Disease Study 2017. Lancet. 2018;392(10159):1859-1922.

42. Global Burden of Disease. 2015 DALYs and HALE Collaborators. Global, regional, and national disability-adjusted life-years (DALYs) for 315 diseases and injuries and healthy life expectancy (HALE), 1990-2015: a systematic analysis for the Global Burden of Disease Study 2015. Lancet. 2016;388(10053):1603-1658.

43. Chan M. Ten Years in Public Health, 2007-2017. Geneva: World Health Organization; 2017.

44. World Bank Group. Forty years later: the extraordinary river blindness partnership sets its sights on new goals [Internet] Washington D.C.: World Bank Group; 2014. Available from: https://www.worldbank.org/en/news/feature/2014/07/03/fortyyears-later-the-extraordinary-river-blindness-partnership-sets-itssights-on-new-goals. Accessed March 4, 2021.

45. World Health Organization. Ending the neglect to attain the sustainable development goals: a road map for neglected tropical diseases 2021-2030. Geneva: World Health Organization; 2020. Available from: https://www.who.int/neglected_diseases/ resources/who-ucn-ntd-2020.01/en/. Accessed February 24, 2021.

46. World Health Organization. London declaration on neglected tropical diseases [internet]. uniting to combat neglected tropical diseases; 2012. Available from: https://unitingtocombatntds.org/ resource-hub/who-resources/london-declaration-neglectedtropical-diseases/. Accessed March 4, 2021.

47. World Health Organization. Accelerating Work to Overcome the Global Impact of Neglected Tropical Diseases - A Roadmap for Implementation. Geneva: World Health Organization; 2012.

48. World Health Organization. Reaching a billion ending neglected tropical diseases: a gateway to Universal Health Coverage fifth progress report on the London declaration on NTDs. Uniting to combat neglected tropical diseases; 2017. Available from: https:// unitingtocombatntds.org/reports/5th-report/. Accessed March 4, 2021.
49. United Nations. Ensure healthy lives and promote well-being for all at all ages [Internet]. New York: United Nations; 2021. Available from: https://sdgs.un.org/goals/goal3. Accessed February 28, 2021.

50. Selvapandiyan A, Croft SL, Rijal S, Nakhasi HL, Ganguly NK. Innovations for the elimination and control of visceral leishmaniasis. PLOS Negl Trop Dis. 2019;13(9):e0007616. doi:10.1371/journal.pntd.0007616

51. The World Bank. Poverty and shared prosperity 2018: piecing together the poverty puzzle [Internet]. New York: The World Bank; 2018. Available from: https://www.worldbank.org/en/publi cation/poverty-and-shared-prosperity-2018. Accessed March 4, 2021.

52. Chaumont C, Kamara K, Baring E, Palacio K, Power A, Lancaster W. The SARS-CoV-2 crisis and its impact on neglected tropical diseases: threat or opportunity? PLOS Negl Trop Dis. 2020;14(9):e0008680. doi:10.1371/journal.pntd.0008680

53. Toor J, Adams ER, Aliee M, et al. Predicted impact of COVID-19 on neglected tropical disease programs and the opportunity for innovation. Clin Infect Dis. 2020; ciaa933.

54. Carvalho SFG, Vieira TM, Moura APV, Andrade MC. Should an intersection between visceral leishmaniasis endemicity and the COVID-19 pandemic be considered? Med Hypotheses. 2020;144:110289. doi:10.1016/j.mehy.2020.110289

55. Ehrenberg JP, Utzinger J, Fontes G, et al. Efforts to mitigate the economic impact of the COVID-19 pandemic: potential entry points for neglected tropical diseases. Infect Dis Poverty. 2021;10(1). doi:10.1186/s40249-020-00790-4.

56. World Health Organization. Global Vector Control Response 2017-2030. Geneva: World Health Organization; 2017.

57. Valero NNH, Uriarte M. Environmental and socioeconomic risk factors associated with visceral and cutaneous leishmaniasis: a systematic review. Parasitol Res. 2020;119(2):365-384.

58. Kirigia JM, Mburugu GN. The monetary value of human lives lost due to neglected tropical diseases in Africa. Infect Dis Poverty. 2017;6(1):165. doi:10.1186/s40249-017-0379-y

59. Pascual Martinez F, Picado A, Roddy P, Palma P. Low castes have poor access to visceral leishmaniasis treatment in Bihar, India. Trop Med Int Health. 2012;17(5):666-673. doi:10.1111/j.13653156.2012.02960.x

60. Kolaczinski JH, Reithinger R, Worku DT, et al. Risk factors of visceral leishmaniasis in East Africa: a case-control study in Pokot territory of Kenya and Uganda. Int J Epidemiol. 2008;37 (2):344-352. doi:10.1093/ije/dym275

61. Lopez K, Tartaglino LC, Steinhorst II, Santini MS, Salomon OD. Risk factors, representations and practices associated with emerging urban human visceral leishmaniasis in Posadas, Argentina. Biomedica. 2016;36:51-63. doi:10.7705/ biomedica.v36i2.2953

62. Ranjan A, Sur D, Singh VP, et al. Risk factors for Indian kala-azar. Am J Trop Med Hyg. 2005;73(1):74-78. doi:10.4269/ ajtmh.2005.73.74

63. Bhowmick AR, Khanum H. Prevalence of visceral leishmaniasis, risk factors and associated disorders: knowledge of inhabitants and professionals in Fulbaria, Mymensingh. Bangladesh J Zool. 2017;45(1):73-83. doi:10.3329/bjz.v45i1.34197

64. Sosa-Estani S, Segura EL, Gomez A, et al. [Cutaneous leishmaniasis in Northern Argentina: identification of risk factors in a case-cohort study of three municipalities in Salta]. Rev Soc Bras Med Trop. 2001;34(6):511-517. Portugese. doi:10.1590/S003786822001000600003

65. Pedrosa Fde A, Ximenes RA. Sociodemographic and environmental risk factors for American cutaneous leishmaniasis (ACL) in the State of Alagoas, Brazil. Am J Trop Med Hyg. 2009;81 (2):195-201. doi:10.4269/ajtmh.2009.81.195 
66. Reithinger R, Mohsen M, Leslie T, Boelaert M. Risk factors for anthroponotic cutaneous Leishmaniasis at the household level in Kabul, Afghanistan. PLoS Negl Trop Dis. 2010;4(3):e639. doi:10.1371/journal.pntd.0000639

67. Alvar J, Yactayo S, Bern C. Leishmaniasis and poverty. Trends Parasitol. 2006;22(12):552-557. doi:10.1016/j.pt.2006.09.004

68. Chappuis F, Sundar S, Hailu A, et al. Visceral leishmaniasis: what are the needs for diagnosis, treatment and control? Nat Rev Microbiol. 2007;5(11):873-882. doi:10.1038/nrmicro1748

69. Rijal S, Koirala S, Van der Stuyft P, Boelaert M. The economic burden of visceral leishmaniasis for households in Nepal. Trans $R$ Soc Trop Med Hyg. 2006;100(9):838-841. doi:10.1016/j. trstmh.2005.09.017

70. Bengtson M, Bharadwaj M, Bosch AT, et al. Matching development of point-of-care diagnostic tests to the local context: a case study of visceral leishmaniasis in Kenya and Uganda. Glob Health Sci Pract. 2020;8(3):549-565. doi:10.9745/GHSP-D-20-00028

71. de Magalhães DF, da Silva JA, Haddad JP, et al. Dissemination of information on visceral leishmaniasis from schoolchildren to their families: a sustainable model for controlling the disease. Cad Saude Publica. 2009;25(7):1642-1646. doi:10.1590/S0102311X2009000700025

72. Thornton SJ, Wasan KM, Piecuch A, Lynd LL, Wasan EK. Barriers to treatment for visceral leishmaniasis in hyperendemic areas: India, Bangladesh, Nepal, Brazil and Sudan. Drug Dev Ind Pharm. 2010;36(11):1312-1319. doi:10.3109/03639041003796648

73. Alvar J, Vélez ID, Bern C, et al. Leishmaniasis worldwide and global estimates of its incidence. PLoS One. 2012;7(5):e35671. doi:10.1371/journal.pone.0035671

74. Weiss DJ, Nelson A, Vargas-Ruiz CA, et al. Global maps of travel time to healthcare facilities. Nat Med. 2020;26(12):1835-1838. doi:10.1038/s41591-020-1059-1

75. Coulborn RM, Gebrehiwot TG, Schneider M, et al. Barriers to access to visceral leishmaniasis diagnosis and care among seasonal mobile workers in Western Tigray, Northern Ethiopia: a qualitative study. PLoS Negl Trop Dis. 2018;12(11):e0006778. doi:10.1371/journal.pntd.0006778

76. Xu K, Evans DB, Kawabata K, Zeramdini R, Klavus J, Murray CJ. Household catastrophic health expenditure: a multicountry analysis. Lancet. 2003;362(9378):111-117. doi:10.1016/S0140-6736(03)13861-5

77. Meheus F, Boelaert M, Baltussen R, Sundar S. Costs of patient management of visceral leishmaniasis in Muzaffarpur, Bihar, India. Trop Med Int Health. 2006;11(11):1715-1724. doi:10.1111/j.1365-3156.2006.01732.x

78. Alves F, Bilbe G, Blesson S, et al. Recent development of visceral leishmaniasis treatments: successes, pitfalls, and perspectives. Clin Microbiol Rev. 2018;31(4):e00048-00018. doi:10.1128/CMR.0004818

79. Okwa OO. Tropical parasitic diseases and women. Ann Afr Med. 2007;6(4):157-163. doi:10.4103/1596-3519.55704

80. Mniouil M, Fellah H, Amarir F, et al. Comparative evaluation of immunochromatographic dipstick test (ICT) rk39, soluble antigen ELISA and IFAT for the sero-diagnosis of visceral leishmaniasis in Morocco. Acta Trop. 2018;182:185-189. doi:10.1016/j. actatropica.2018.03.007

81. Devi SC, Saravanan H, Joseph RE, Koturan S, Srinivasan MV. Leishmaniasis: a review on global epidemiological trends. Res J Pharm Technol. 2014;7(5):569-574.

82. Guerin PJ, Olliaro P, Sundar S, et al. Visceral leishmaniasis: current status of control, diagnosis, and treatment, and a proposed research and development agenda. Lancet Infect Dis. 2002;2(8):494-501. doi:10.1016/S1473-3099(02)00347-X
83. Chappuis F, Rijal S, Soto A, Menten J, Boelaert M. A meta-analysis of the diagnostic performance of the direct agglutination test and rK39 dipstick for visceral leishmaniasis. BMJ. 2006;333(7571):723. doi:10.1136/ bmj.38917.503056.7C

84. Gebreyohannes EA, Bhagvathula AS, Abegaz TM, Seid MA. Treatment outcomes of visceral leishmaniasis in Ethiopia from 2001 to 2017: a systematic review and meta-analysis. Infect Dis Poverty. 2018;7(1):108. doi:10.1186/s40249-018-0491-7

85. Abongomera C, Diro E, Vogt F, et al. The risk and predictors of visceral leishmaniasis relapse in human immunodeficiency virus-coinfected patients in Ethiopia: a retrospective cohort study. Clin Infect Dis. 2017;65(10):1703-1710. doi:10.1093/cid/cix607

86. Munoz Boudet AM, Buitrago P, Leroy De La Briere B, et al. Gender differences in poverty and household composition through the life-cycle: a global perspective. World Bank Policy Res Working Paper. 2018;(8360).

87. Christensen M. Feminisation of poverty: causes and implications. In: Leal Filho W, Azul A, Brandli L, Özuyar P, Wall T, editors. Gender Equality. Encyclopedia of the UN Sustainable Development Goals. Cham: Springer; 2019. doi:10.1007/9783-319-70060-1_6-1.

88. Al-Kamel MA. Impact of leishmaniasis in women: a practical review with an update on my ISD-supported initiative to combat leishmaniasis in Yemen (ELYP). Int J Womens Dermatol. 2016;2 (3):93-101. doi:10.1016/j.ijwd.2016.04.003

89. Hamdam P. Why does leishmaniasis result in life-long scars for women in Afghanistan? Public Health. 2020;185:196-198. doi:10.1016/j.puhe.2020.05.039

90. Bilgic-Temel A, Murrell DF, Uzun S. Cutaneous leishmaniasis: a neglected disfiguring disease for women. Int $J$ Womens Dermatol. 2019;5(3):158-165. doi:10.1016/j.ijwd.2019.01.002

91. Diro E, Lynen L, Ritmeijer K, Boelaert M, Hailu A, van Griensven J. Visceral Leishmaniasis and HIV coinfection in East Africa. PLoS Negl Trop Dis. 2014;8(6):e2869. doi:10.1371/ journal.pntd.0002869

92. Diro E, Edwards T, Ritmeijer K, et al. Long term outcomes and prognostics of visceral leishmaniasis in HIV infected patients with use of pentamidine as secondary prophylaxis based on CD4 level: a prospective cohort study in Ethiopia. PLoS Negl Trop Dis. 2019;13 (2):e0007132. doi:10.1371/journal.pntd.0007132

93. Nweze JA, Nweze EI, Onoja US. Nutrition, malnutrition, and leishmaniasis. Nutrition. 2020;73:110712. doi:10.1016/j. nut.2019.110712

94. Bantie K, Tessema F, Massa D, Tafere Y. Factors associated with visceral leishmaniasis infection in North Gondar Zone, Amhara Region, North West Ethiopia, case control study. Sci J Public Health. 2014;2(6):560-568.

95. Yared S, Deribe K, Gebreselassie A, et al. Risk factors of visceral leishmaniasis: a case control study in north-western Ethiopia. Parasit Vectors. 2014;7:470. doi:10.1186/s13071-014-0470-1

96. Lindoso JAL, Moreira CHV, Cunha MA, Queiroz IT. Visceral leishmaniasis and HIV coinfection: current perspectives. HIV AIDS (Auckl). 2018;10:193-201. doi:10.2147/HIV.S143929

97. World Health Organization. Report of the Fifth Consultative Meeting on Leishmania/HIV Coinfection. Addis Ababa, Ethiopia: World Health Organization; 2007.

98. Malla N, Mahajan RC. Pathophysiology of visceral leishmaniasis - some recent concepts. Indian J Med Res. 2006;123(3):267-274.

99. Alvar J, Aparicio P, Aseffa A, et al. The relationship between leishmaniasis and AIDS: the second 10 years. Clin Microbiol Rev. 2008;21 (2):334-359, table of contents. doi:10.1128/CMR.00061-07 
100. Dwyer-Lindgren L, Cork MA, Sligar A, et al. Mapping HIV prevalence in sub-Saharan Africa between 2000 and 2017. Nature. 2019;570(7760):189-193. doi:10.1038/s41586-019-1200-9

101. Asenso-Okyere K, Aragon C, Thangata P, Andam K, Mekonnen DA. HIV and AIDS and farm labor productivity: a review of recent evidence in Africa. J Dev Agric Econ. 2010;2(12):406-415.

102. World Health Organization. Leishmaniasis Epidemiological Report of the Americas. Pan American Health Organization and World Health Organization; 2019.

103. Ejara ED, Lynen L, Boelaert M, Van Griensven J. Challenges in HIV and visceral Leishmania co-infection: future research directions. Trop Med Int Health. 2010;15(10):1266-1267. doi:10.1111/j.1365-3156.2010.02612.x

104. Zijlstra EE, Valenzuela JG. PKDL and other dermal lesions in HIV co-infected patients with Leishmaniasis: review of clinical presentation in relation to immune responses. PLoS Negl Trop Dis. 2014;8(11):e3258. doi:10.1371/journal.pntd.0003258

105. Cota GF, de Sousa MR, de Assis TSM, Pinto BF, Rabello A. Exploring prognosis in chronic relapsing visceral leishmaniasis among HIV-infected patients: circulating Leishmania DNA. Acta Trop. 2017;172:186-191. doi:10.1016/j.actatropica.2017.05.011

106. Lindoso JA, Cunha MA, Queiroz IT, Moreira CH. LeishmaniasisHIV coinfection: current challenges. HIV AIDS (Auckl). 2016;8:147-156. doi:10.2147/HIV.S93789

107. Ferreira GR, Castelo branco ribeiro JC, Meneses Filho A, et al. Human competence to transmit leishmania infantum to lutzomyia longipalpis and the influence of human immunodeficiency virus infection. $\mathrm{Am}$ J Trop Med Hyg. 2018;98(1):126-133. doi:10.4269/ajtmh.16-0883

108. World Health Organization. Leishmaniasis and HIV coinfection. Geneva: World Health Organization; 2021. Available from: https://www.who.int/leishmaniasis/burden/hiv_coinfection/bur den_hiv_coinfection/en/. Accessed February 24, 2021.

109. International Organization for Migration. World Migration Report 2020. Geneva: International Organization for Migration; 2019.

110. Al-Salem WS, Pigott DM, Subramaniam K, et al. Cutaneous leishmaniasis and conflict in Syria. Emerg Infect Dis. 2016;22 (5):931-933. doi:10.3201/eid2205.160042

111. Du R, Hotez PJ, Al-Salem WS, Acosta-Serrano A, Rafati S. Old world cutaneous leishmaniasis and refugee crises in the Middle East and North Africa. PLOS Negl Trop Dis. 2016;10(5): e0004545. doi:10.1371/journal.pntd.0004545

112. Bhattacharya SK, Dash AP. Elimination of Kala-Azar from the Southeast Asia Region. Am J Trop Med Hyg. 2017;16-0279.

113. Reithinger R, Brooker S, Kolaczinski JH. Visceral leishmaniasis in eastern Africa - current status. T Roy Soc Trop Med H. 2007;101(12):1169-1170. doi:10.1016/j.trstmh.2007.06.001

114. Butler CD, Hanigan IC. Anthropogenic climate change and health in the Global South. Int $J$ Tuberc Lung D. 2019;23 (12):1243-1252. doi:10.5588/ijtld.19.0267

115. The LA. Commission on climate change. Lancet. 2009;373 (9676):1659. doi:10.1016/S0140-6736(09)60922-3

116. El-Sayed A, Kamel M. Climatic changes and their role in emergence and re-emergence of diseases. Environ Sci Pollut $R$. 2020;27(18):22336-22352. doi:10.1007/s11356-020-08896-w

117. Ready PD. Leishmaniasis emergence and climate change. Revue Scientifique Et Technique (International Office of Epizootics). 2008;27:399-412.

118. Dhimal M, Ahrens B, Kuch U, Baylis M. Climate change and spatiotemporal distributions of vector-borne diseases in Nepal-a systematic synthesis of literature. PLoS One. 2015;10(6): e0129869. doi:10.1371/journal.pone.0129869

119. Ready PD. Leishmaniasis emergence in Europe. Euro Surveill. 2010;15(10):19505. doi:10.2807/ese.15.10.19505-en
120. Ribeiro CJN, Dos santos AD, Lima SVMA, et al. Space-time risk cluster of visceral leishmaniasis in Brazilian endemic region with high social vulnerability: an ecological time series study. PLOS Negl Trop Dis. 2021;15(1):e0009006. doi:10.1371/journal.pntd.0009006

121. Henke O, Mapendo PJ, Mremi A, et al. Skin maculae, chronic diarrhea, cachexia, and splenomegaly - Late presentation of the first autochthonous case of visceral leishmaniasis in Tanzania. PLOS Neg Trop Dis. 2021;15(1):e0008925. doi:10.1371/journal.pntd.0008925

122. Outbreak News Today. Kenya: four Leishmaniasis deaths reported in Kitui County, Kenya. Tampa: Outbreak News Today; 2020. Available from: http://outbreaknewstoday.com/ kenya-four-leishmaniasis-deaths-reported-in-kitui-county-kenya -57120/. Accessed February 21, 2021.

123. Alamin AA. Visceral leishmaniasis in a non-endemic region of Eritrea. Cureus. 2020. doi:10.7759/cureus.11318

124. Sunyoto T, Potet J, Boelaert M, Satoskar AR. Visceral leishmaniasis in Somalia: a review of epidemiology and access to care. PLOS Negl Trop Dis. 2017;11(3):e0005231. doi:10.1371/journal. pntd.0005231

125. Zaidi F, Fatima SH, Jan T, et al. Environmental risk modelling and potential sand fly vectors of cutaneous leishmaniasis in Chitral district: a leishmanial focal point of mount Tirich Mir, Pakistan. Trop Med Int Health. 2017;22(9):1130-1140. doi:10.1111/tmi.12916

126. Zhu C, Kobayashi K, Loladze I, et al. Carbon dioxide (CO2) levels this century will alter the protein, micronutrients, and vitamin content of rice grains with potential health consequences for the poorest rice-dependent countries. Sci Adv. 2018;4(5): eaaq1012. doi:10.1126/sciadv.aaq1012

127. Smith MR, Myers SS. Impact of anthropogenic CO2 emissions on global human nutrition. Nat Clim Chang. 2018;8(9):834-839. doi:10.1038/s41558-018-0253-3

128. Burrows K, Kinney P. Exploring the climate change, migration and conflict nexus. Int $J$ Environ Res Public Health. 2016;13 (4):443. doi:10.3390/ijerph13040443

129. Jean F, Médecins Sans FR. Life, Death, and Aid: The Médecins Sans Frontières Report on World Crisis Intervention. London, New York: Routledge; 1993.

130. Beer P, Harith A, Grootheest M, Winkler A. Outbreak of kala-azar in the Sudan. Lancet. 1990;335(8683):224. doi:10.1016/0140-6736(90)90313-T

131. Seaman J, Mercer AJ, Sondorp E. The epidemic of visceral leishmaniasis in Western Upper Nile, Southern Sudan: course and impact from 1984 to 1994. Int J Epidemiol. 1996;25 (4):862-871. doi:10.1093/ije/25.4.862

132. Jacobsen RL. Leishmaniasis in an era of conflict in the Middle East. Vector Borne Zoonotic Dis. 2011;11(3):247-258. doi:10.1089/vbz.2010.0068

133. Alawieh A, Musharrafieh U, Jaber A, Berry A, Ghosn N, Bizri AR. Revisiting leishmaniasis in the time of war: the Syrian conflict and the Lebanese outbreak. Int $J$ Infect Dis. 2014;29:115-119. doi:10.1016/j.ijid.2014.04.023

134. Saroufim M, Charafeddine K, Issa G, et al. Ongoing epidemic of cutaneous leishmaniasis among Syrian Refugees, Lebanon1. Emerg Infect Dis. 2014;20(10):1712-1715. doi:10.3201/ eid2010.140288

135. Hayani K, Dandashli A, Weisshaar E. Cutaneous leishmaniasis in Syria: clinical features, current status and the effects of war. Acta Derm Venereol. 2015;95(1):62-66. doi:10.2340/00015555-1988

136. Ostfelt RS, Keesing F. Planetary health and infectious disease. In: Myers S, Frumkin H, editors. Planetary Health: Protecting Nature to Protect Ourselves. Washington DC: Island Press; 2020:141-164. 
137. Hlavacova J, Votypka J, Volf P. The effect of temperature on Leishmania (Kinetoplastida: trypanosomatidae) development in sand flies. J Med Entomol. 2013;50(4):955-958. doi:10.1603/ME13053

138. Fischer D, Moeller P, Thomas SM, Naucke TJ, Beierkuhnlein C. Combining climatic projections and dispersal ability: a method for estimating the responses of sandfly vector species to climate change. PLoS Negl Trop Dis. 2011;5(11):e1407. doi:10.1371/journal.pntd.0001407

139. Chalghaf B, Chemkhi J, Mayala B, et al. Ecological niche modeling predicting the potential distribution of Leishmania vectors in the Mediterranean basin: impact of climate change. Parasit Vectors. 2018;11(1):461. doi:10.1186/s13071-018-3019-x

140. Cazan CD, Păstrav IR, Ionică AM, et al. Updates on the distribution and diversity of sand flies (Diptera: psychodidae) in Romania. Parasit Vectors. 2019;12(1). doi:10.1186/s13071-0193507-7.

141. Oerther S, Jöst H, Heitmann A, et al. Phlebotomine sand flies in Southwest Germany: an update with records in new locations. Parasit Vectors. 2020;13(1). doi:10.1186/s13071-020-04058-6.

142. Dvorak V, Kasap OE, Ivovic V, et al. Sand flies (Diptera: psychodidae) in eight Balkan countries: historical review and region-wide entomological survey. Parasit Vectors. 2020;13 (1):573. doi:10.1186/s13071-020-04448-w

143. Sarnoff R, Desai J, Desjeux P, et al. The economic impact of visceral leishmaniasis on rural households in one endemic district of Bihar, India. Trop Med Int Health. 2010;15(Suppl 2):42-49. doi:10.1111/j.1365-3156.2010.02516.x

144. Ahluwalia IB, Bern C, Costa C, et al. Visceral leishmaniasis: consequences of a neglected disease in a Bangladeshi community. Am J Trop Med Hyg. 2003;69(6):624-628. doi:10.4269/ajtmh.2003.69.624

145. Kalteh EA, Rajabzadeh R, Sofizadeh A, Fadaei E, Sabery S, Saghafipour A. Economic burden of cutaneous leishmaniasis in Golestan Province. J N Khorasan Med Sci. 2019;10(4):1-8.

146. Salimi M, Saghafipour A, Hamidi Parsa H, Khosravi M, Shirzadi MR. Economic burden evaluation of cutaneous leishmaniasis in Iran. Shiraz E Med J. 2019;20(6):e82810. doi:10.5812/ semj. 82810

147. Wijerathna T, Gunathilaka N, Gunawardena K. The economic impact of cutaneous leishmaniasis in Sri Lanka. Biomed Res Int. 2018;2018:3025185. doi:10.1155/2018/3025185

148. Galvao EL, Assis TSM, Pedras MJ, Cota GF, Simoes TC, Rabello A. Economic impact of localized cutaneous leishmaniasis on adult patients of a referral service in Belo Horizonte, Minas Gerais State, Brazil. Cad Saude Publica. 2020;36(7):e00136419. doi:10.1590/0102-311x00136419

149. Kankeu HT, Saksena P, Xu K, Evans DB. The financial burden from non-communicable diseases in low- and middle-income countries: a literature review. Health Res Policy Syst. 2013;11:31. doi:10.1186/1478-4505-11-31

150. Adhikari S, Maskay N. Economic cost and consequences of Kala-Azar in Danusha and Mahottari districts of Nepal. Indian J Commun Med. 2005;30:121-125.

151. Adhikari SR, Maskay NM, Sharma BP. Paying for hospital-based care of Kala-azar in Nepal: assessing catastrophic, impoverishment and economic consequences. Health Policy Plan. 2009;24 (2):129-139. doi:10.1093/heapol/czn052

152. Tachfouti N, Najdi A, Alonso S, et al. Cost of pediatric visceral leishmaniasis care in Morocco. PLoS One. 2016;11(6):e0155482. doi:10.1371/journal.pone.0155482

153. Assis TSM, Rosa DCP, Teixeira EM, et al. The direct costs of treating human visceral leishmaniasis in Brazil. Rev Soc Bras Med Trop. 2017;50(4):478-482. doi:10.1590/0037-8682-01332017
154. De carvalho I, Peixoto HM, Romero GAS, de Oliveira MRF. Cost of visceral leishmaniasis care in Brazil. Trop Med Int Health. 2017;22(12):1579-1589. doi:10.1111/tmi.12994

155. Reithinger R, Coleman PG. Treating cutaneous leishmaniasis patients in Kabul, Afghanistan: cost-effectiveness of an operational program in a complex emergency setting. BMC Infect Dis. 2007;7:3. doi:10.1186/1471-2334-7-3

156. Bailey F, Mondragon-Shem K, Haines LR, et al. Cutaneous leishmaniasis and co-morbid major depressive disorder: a systematic review with burden estimates. PLoS Negl Trop Dis. 2019;13(2):e0007092. doi:10.1371/journal.pntd.0007092

157. Al-Kamel MA. Stigmata in cutaneous leishmaniasis: historical and new evidence-based concepts. Our Dermatol Online. 2017;8 (1):81-90. doi:10.7241/ourd.20171.21

158. Kassi M, Kassi M, Afghan AK, Rehman R, Kasi PM. Marring leishmaniasis: the stigmatization and the impact of cutaneous leishmaniasis in Pakistan and Afghanistan. PLoS Negl Trop Dis. 2008;2(10):e259. doi:10.1371/journal.pntd.0000259

159. Reithinger R, Aadil K, Kolaczinski J, Mohsen M, Hami S. Social impact of leishmaniasis, Afghanistan. Emerg Infect Dis. 2005;11 (4):634-636. doi:10.3201/eid1104.040945

160. Khatami A, Emmelin M, Talaee R, et al. Lived experiences of patients suffering from acute old world cutaneous leishmaniasis: a qualitative content analysis study from Iran. J Arthropod Borne Dis. 2018;12(2):180-195. doi:10.18502/jad.v12i2.44

161. Vares B, Mohseni M, Heshmatkhah A, et al. Quality of life in patients with cutaneous leishmaniasis. Arch Iran Med. 2013;16(8):474-477.

162. Bennis I, Belaid L, De Brouwere V, Filali H, Sahibi H, Boelaert M. "The mosquitoes that destroy your face". Social impact of Cutaneous Leishmaniasis in South-eastern Morocco, A qualitative study. PLoS One. 2017;12(12):e0189906. doi:10.1371/journal.pone.0189906

163. Alemayehu M, Wubshet M, Mesfin N, Gebayehu A. Perceived quality of life among Visceral Leishmaniasis and HIV coinfected migrant male-workers in Northwest Ethiopia: a qualitative study. BMC Public Health. 2017;17(1):204. doi:10.1186/s12889-017-4132-z

164. Nair M, Kumar P, Pandey S, et al. Quality of life perceptions amongst patients co-infected with Visceral Leishmaniasis and HIV: a qualitative study from Bihar, India. PLoS One. 2020;15 (2):e0227911. doi:10.1371/journal.pone.0227911

165. Garapati P, Pal B, Siddiqui NA, et al. Knowledge, stigma, health seeking behaviour and its determinants among patients with post kala azar dermal leishmaniasis, Bihar, India. PLoS One. 2018;13 (9):e0203407. doi:10.1371/journal.pone.0203407

166. Pal B, Murti K, Siddiqui NA, et al. Assessment of quality of life in patients with post kala azar dermal leishmaniasis. Health Qual Life Outcomes. 2017;15(1):148. doi:10.1186/s12955-017-0720-y

167. Kuper H. Disability, mental health, stigma and discrimination and neglected tropical diseases. Trans R Soc Trop Med Hyg. 2021;115 (2):145-146. doi:10.1093/trstmh/traa160

168. World Health Organization. Mental Health of People with Neglected Tropical Diseases: Towards a Person-Centred Approach. Geneva: World Health Organization; 2020.

169. Furuse Y. Analysis of research intensity on infectious disease by disease burden reveals which infectious diseases are neglected by researchers. Proc Natl Acad Sci U S A. 2019;116(2):478-483. doi:10.1073/pnas.1814484116

170. Mueller YK, Kolaczinski JH, Koech T, et al. Clinical epidemiology, diagnosis and treatment of visceral leishmaniasis in the Pokot endemic area of Uganda and Kenya. Am J Trop Med Hyg. 2014;90(1):33-39. doi:10.4269/ajtmh.13-0150

171. Bush JT, Wasunna M, Alves F, et al. Systematic review of clinical trials assessing the therapeutic efficacy of visceral leishmaniasis treatments: a first step to assess the feasibility of establishing an individual patient data sharing platform. PLoS Negl Trop Dis. 2017;11(9):e005781. doi:10.1371/journal.pntd.0005781 
172. Lenk EJ, Redekop WK, Luyendijk M, et al. Socioeconomic benefit to individuals of achieving 2020 targets for four neglected tropical diseases controlled/eliminated by innovative and intensified disease management: human African trypanosomiasis, leprosy, visceral leishmaniasis, Chagas disease. PLoS Negl Trop Dis. 2018;12(3):e0006250. doi:10.1371/journal. pntd.0006250

173. Kim S, Nguyen V, Lee H, Seo J, Jeong H. Economic evaluations of interventions to prevent or control major neglected tropical diseases in low and middle-income countries: a systematic review. 2020.

174. World Health Organization. Neglected tropical diseases: impact of COVID-19 and WHO's response. Wkly Epidemiolog Record. 2020;95:461-468.

175. Olesen OF, Iqbal Parker M. Health research in Africa: getting priorities right. Trop Med Int Health. 2012;17(9):1048-1052. doi:10.1111/j.1365-3156.2012.03027.x

176. Global Burden of Disease Health Financing Collaborator Network; Dieleman JL, Haakenstad A, Micah A. Spending on health and HIV/AIDS: domestic health spending and development assistance in 188 countries, 1995-2015. Lancet. 2018;391 (10132):1799-1829. doi:10.1016/S0140-6736(18)30698-6
177. Liese BH, Houghton N, Teplitskaya L. Development assistance for neglected tropical diseases: progress since 2009. Int Health. 2014;6(3):162-171. doi:10.1093/inthealth/ihu052

178. World Bank Country and Lending Groups. New York: The World Bank; 2021. Available from: https://datahelpdesk.worldbank.org/ knowledgebase/articles/906519-world-bank-country-and-lendinggroups. Accessed February 26, 2021.

179. Department of Economic and Social Affairs World Population Prospects. United Nations website; 2019. Available from: https:// population.un.org/wpp/Download/Standard/Population/. Accessed February 26, 2021.

180. Pigott DM, Bhatt S, Golding N, et al. Data from: global distribution maps of the Leishmaniases. Dryad Dataset. 2015. doi:10.5061/dryad.05f5h

181. Poverty headcount ratio at $\$ 1.90$ a day (2011 PPP) (\% of population) [Internet]. New York: The World Bank; 2020. Available from: https:// data.worldbank.org/indicator/SI.POV.DDAY. Accessed February 26, 2020
Research and Reports in Tropical Medicine

\section{Publish your work in this journal}

Research and Reports in Tropical Medicine is an international, peerreviewed, open access journal publishing original research, case reports, editorials, reviews and commentaries on all areas of tropical medicine, including: Diseases and medicine in tropical regions; Entomology; Epidemiology; Health economics issues; Infectious disease; Laboratory science and new technology in tropical medicine;

\section{Dovepress}

Parasitology; Public health medicine/health care policy in tropical regions; and Microbiology. The manuscript management system is completely online and includes a very quick and fair peer-review system. Visit http://www.dovepress.com/testimonials.php to read real quotes from published authors. 